\title{
A kinetic study on the aggregation behavior of $\beta$-amyloid peptides in different initial solvent environments
}

\author{
Steven S.-S. Wang*, Ya-Ting Chen, Po-Han Chen, Kuan-Nan Liu \\ Department of Chemical Engineering, National Taiwan University, No. 1, Sec. 4, Roosevelt Road, Taipei 106, Taiwan
}

Received 15 October 2004; accepted 25 February 2005

\begin{abstract}
$\beta$-Amyloid peptide $(\mathrm{A} \beta)$ is the major proteinacious constituent of senile plaques in Alzheimer's disease and is believed to be responsible for the neurodegeneration associated with the disease. This work is aimed at determining the effect of solvent environment on the aggregation kinetics of $\mathrm{A} \beta$ peptides. Prior to dilution into phosphate buffer saline, we have used three different initial solvent systems, $0.1 \%$ (v/v) trifluoroacetic acid in deionized water, $100 \%(\mathrm{v} / \mathrm{v})$ dimethylsulfoxide, and $8 \mathrm{M}$ urea to solubilize A $\beta$ peptides. Our research shows that the increase in ThT fluorescence intensity or absorbance elicited by aggregated species of A $\beta$ peptides exhibited a solvent environmentdependent behavior. Results from $A \beta$ aggregation in trifluoroacetic acid-phosphate buffer saline and dimethylsulfoxide-phosphate buffer saline systems suggested the involvement of the seeding effect. Moreover, with the aid of three proposed reaction schemes, the effect of this solvent environment-dependent behavior was quantitatively analyzed. We believe that a better understanding of how A $\beta$ species and its derivatives aggregate/self-assemble will shed light on the design and analysis of future work in this area.
\end{abstract}

(C) 2005 Elsevier B.V. All rights reserved.

Keywords: Alzheimer's disease; $\beta$-Amyloid; Aggregation; Kinetics; Solvent

\section{Introduction}

Alzheimer's disease (AD) is the leading cause of dementia in the aging population, affecting over 6.9 million people worldwide annually [8]. Although AD can be diagnosed via evaluation of the symptoms, it is not confirmed until a post-mortem examination of the brain tissue has been performed. While Alzheimer's disease and other conformational diseases have been the center of intense research efforts, effective treatments are still unavailable. Critical gaps in the knowledge regarding this area still exist, alluding to the profound importance of conducting more fundamental research. The defining pathological feature of Alzheimer's disease observed in an autopsy is the formation and progressive deposition of insoluble amyloid fibrils within the cerebral cortex [43].

A 39-43 amino acid long $\beta$-amyloid peptide (A $\beta)$, a proteolytic product of a much larger amyloid precursor protein

\footnotetext{
* Corresponding author. Tel.: +886 23366 5870; fax: +886 223623040

E-mail address: sswang@ntu.edu.tw (S.S.-S. Wang).
}

(APP), is the major protein constituent of senile plaques [44]. $\mathrm{A} \beta$, a small protein with the molecular weight on the order of $4 \mathrm{kDa}$, self assembles into a larger fibrillar structure several microns in length. Dramatic neuron loss and/or neuron deterioration are normally observed in the vicinity of senile plaques.

It is widely, but not universally, believed that the extracellular aggregation of $A \beta$ into fibrils in $A D$ is a causative event in the neurodegeneration observed in the disease and this $A \beta$ peptide, when aggregated, may serve as a significant contributing factor in the onset or progression of $\mathrm{AD}$. Mounting evidence originating from in vitro toxicity studies with synthetic $A \beta$ peptides shows that $A \beta$, in an aggregated state (fibril, protofibril, low molecular weight oligomer, or diffusible, non-fibrillar ligand), is toxic to neurons in cultures $[6,14,15,42,53]$.

Different solvent systems such as trifluoroacetic acid (TFA), dimethylsulfoxide (DMSO), and urea used for manipulating the initial state of $A \beta$ were often implemented in past $A \beta$-related researches. It has been suggested that the kind of solvent used to dissolve lyophilized $A \beta$ peptide determines 
not only the initial conformation of $\mathrm{A} \beta$ but also the following aggregation kinetic behavior.

As noted earlier, various dissolving systems including DMSO-PBS, TFA-PBS, and urea-PBS, were utilized by different researchers in a variety of studies associated with $A \beta$. It is widely recognized that the solvent utilized to dissolve the lyophilized peptide influence the starting confirmation and aggregation state. However, very few reports were presented to closely examine the difference caused by the selection of solvent systems. In the present work, we examined the effect of dissolving solvents on the kinetic behavior of $\beta$ amyloid peptide during the course of aggregation. Commonly used synthetic model peptide, $A \beta(1-40)$, and its partial fragments, $A \beta(25-35)$, and $A \beta(1-16)$, were utilized in this study. Along with the experimental measurement of aggregation properties, three mathematical kinetic models were utilized for quantitative assessment purposes. We believe that a better understanding, from the kinetic perspective, of how $\mathrm{A} \beta$ species and its derivatives aggregate/self-assemble, will shed light on the design and analysis of future work in this area.

\section{Materials and methods}

\subsection{Materials}

Synthetic $A \beta(1-16), A \beta(25-35)$, and $A \beta(1-40)$ peptides were purchased from Biosource International (Camarillo, CA, USA). All other chemicals, unless otherwise specified, were obtained from Sigma (St. Louis, MO, USA).

\subsection{A $\beta$ peptide solution preparation}

Stock solutions of $10 \mathrm{mg} / \mathrm{mL}$ were prepared by dissolving the $A \beta(25-35)$ or $A \beta(1-40)$ peptides in $0.1 \%(v / v)$ trifluoroacetic acid in deionized water or $100 \%(\mathrm{v} / \mathrm{v})$ dimethylsulfoxide. After incubating for $1 \mathrm{~h}$ at $25^{\circ} \mathrm{C}$, the peptide stock solutions were diluted in phosphate buffer saline (PBS, $13.67 \mathrm{mM} \mathrm{NaCl}, 2.68 \mathrm{mM} \mathrm{KCl}, 10 \mathrm{mM} \mathrm{Na}_{2} \mathrm{HPO}_{4}, 1.76 \mathrm{mM}$ $\left.\mathrm{KH}_{2} \mathrm{PO}_{4}, \mathrm{pH} 7.2\right)$ to the concentrations $(50 \mu \mathrm{M})$ used in the experiment. Other researchers have indicated that $A \beta$ peptide in $8 \mathrm{M}$ urea $\mathrm{pH} 10$ forms an unstructured monomer [36]. To form an unstructured monomeric $A \beta$ from urea, lyophilized $\mathrm{A} \beta$ peptide was dissolved using $8 \mathrm{M}$ urea in $10 \mathrm{mM}$ glycine- $\mathrm{NaOH}$ buffer, $\mathrm{pH} 10$ at a concentration of $10 \mathrm{mg} / \mathrm{mL}$. After incubating for $1 \mathrm{~h}$ at $25^{\circ} \mathrm{C}$, the peptide sample was diluted in $8 \mathrm{M}$ urea to the concentration $(50 \mu \mathrm{M})$ used in the experiment. These final sample solutions were rotated at $60 \mathrm{rpm}$ at $25^{\circ} \mathrm{C}$ during the course of aggregation process.

\subsection{Spectroscopic aggregation analysis}

Absorbance at $405 \mathrm{~nm}$ was monitored at different times. Three hundred microliters of $A \beta$ samples taken at different times were added to a well of 96-well plate. The absorbance was measured using a $\mu$ Quant Microplate reader (Bio-Tek Instruments, VT, USA). In order to well suspend the fibrillar species, the $A \beta$ sample solutions were mixed by vortexing prior to each absorbance measurement.

\subsection{Thioflavin T fluorescence (ThT) assay}

Forty microliters of $A \beta$ samples taken at different times were mixed with $960 \mu \mathrm{L}$ of $10 \mu \mathrm{M}$ thioflavine $\mathrm{T}$ (ThT) in phosphate buffer saline (PBS). Changes in ThT fluorescence, which would indicate the presence of amyloid fibrils [27], were measured by exciting samples at $437 \mathrm{~nm}$ and measuring emission intensities at $485 \mathrm{~nm}$ using a F-2500 Fluorescence Spectrophotometer (Hitachi, Japan).

\subsection{ANS-binding assay}

Three hundred and fifty microliters of $A \beta$ sample in different buffer solutions were mixed with $450 \mu \mathrm{L}$ of $20 \mathrm{mM}$ 1-anilinonaphthalene-8-sulfonic acid (ANS) in PBS. Mixtures taken at different times were analyzed using a F-2500 Fluorescence Spectrophotometer (Hitachi, Japan). The excitation was set at $380 \mathrm{~nm}$ and the total fluorescence emission was recorded between 420 and $580 \mathrm{~nm}$.

\subsection{Electron microscopy}

A $20 \mu \mathrm{l}$ sample was fixed for $15 \mathrm{~min}$ in $0.25 \%$ glutaraldehyde (Electron Microscopy Sciences, Hatfield, PA, USA) in PBS, pH 7.2. The sample was then diluted 1:10 with deionized water; $6 \mu$ l of diluted sample were placed on carbon stabilized, formvar coated grids. Grids were negatively stained with $2 \%(w / v)$ aqueous uranyl acetate (Electron Microscopy Sciences, Hatfield, PA, USA) and then examined and photographed in a JEOL, JEM-1200EX II transmission electron microscope (Tokyo, Japan) at an accelerating voltage of $80 \mathrm{kV}$.

\subsection{Statistical analysis}

All data represent means \pm standard deviation (S.D.) for $n$ independent determinations. Specific $n$ values are given in figure legends.

\section{Results and discussion}

\subsection{Selection of initial solubilization systems}

Several stock solvent systems have been used in past in vitro $A \beta$-related researches. Trifluoroacetic acid is the commonly used ion-pairing agent in the purification steps of synthetic $A \beta$. A number of researchers utilized TFA to prepare $A \beta(1-40)$ stock solution and it has been consistently shown that $A \beta(1-40)$ peptide exhibited random coil 
structure when prepared from TFA. Therefore, $0.1 \%(\mathrm{v} / \mathrm{v})$ TFA in deionized water was the first stock solvent of our choice. Dimethylsulfoxide is a polar aprotic solvent and normally serves as a hydrogen bond acceptor. Past studies showed that the hydrogen bond formed between DMSO and water are stronger than that between water molecules [29-31]. Majority of the studies often used pure DMSO to destabilize the secondary structures ( $\beta$-sheet) of $A \beta[46]$ and to render the initial $A \beta$ condition with higher percentage of unstructured species (monomer) [11]. Here, DMSO was chosen as our second dissolving solvent. In fact, both TFA and DMSO have also been used for solubilization of preformed aggregated species (or seeds).

Urea was often used as a denaturant for protein folding studies $[7,10]$. Evidence showed that proteins/polypeptides were unfolded to exhibit random coil structure in the presence of urea [2,4]. Also, $A \beta$ fibril formation was found to be retarded when $\mathrm{pH}$ is higher than 9 [5]. In order to start with a more homogeneous population of $A \beta(1-40)$ in its unfolded monomeric state, Pallitto and Murphy used $8 \mathrm{M}$ urea at $\mathrm{pH}$ 10 to solubilize $A \beta$ peptide [36]. In this study, $8 \mathrm{M}$ urea at $\mathrm{pH} 10$ served as our third dissolving solvent prior to dilution into PBS buffer.

\subsection{Aggregation behavior monitored via thioflavin $T$ fluorescence}

An increase in ThT fluorescence has been reported as an important indicator of the presence of amyloid fibril [27]. ThT is believed to interact fairly specifically and rapidly with amyloid fibrils, and the sequence/or primary structure of proteins has negligible effect on the binding between ThT and protein molecules [26]. To investigate the aggregation kinetics of $\beta$-amyloid peptide, we first monitored the changes of ThT fluorescence intensity of $A \beta(1-40), A \beta(25-35)$, and $\mathrm{A} \beta(1-16)$ as a function of incubation time. As seen in Fig. 1A, the increase in ThT fluorescence indicates amyloid/aggregate formation in $A \beta(1-40)$ samples prepared by dilution in PBS from stock solutions in $100 \%$ DMSO or $0.1 \%$ (v/v) TFA. The maximal fluorescence intensities for samples of $100 \%$ DMSO-PBS, $0.1 \%$ (v/v) TFA-PBS, and $8 \mathrm{M}$ urea-PBS are approximately 305,370 , and 320 units, respectively. No significant increase in ThT fluorescence intensities was observed at 125,125 , and $175 \mathrm{~h}$ after the initiation of self-assembly for $\mathrm{A} \beta$ pre-dissolved in $100 \%$ DMSO, $0.1 \%$ (v/v) TFA, or $8 \mathrm{M}$ urea, respectively.

We also measured the ThT fluorescence for $A \beta(1-16)$ and $A \beta(25-35)$ during the course of aggregation. As depicted in Fig. 1B, $A \beta(25-35)$ peptide exhibited similar ThT fluorescence pattern as $A \beta(1-40)$ and the fluorescence intensity increased with the progression of aggregation. However, $A \beta(25-35)$ fluoresced with a much smaller intensity relative to that of $A \beta(1-40)$. Regardless of the solvents used, no detectable changes in ThT fluorescence intensity were observed with $A \beta(1-16)$ peptide samples relative to the buffer solution (data not shown).
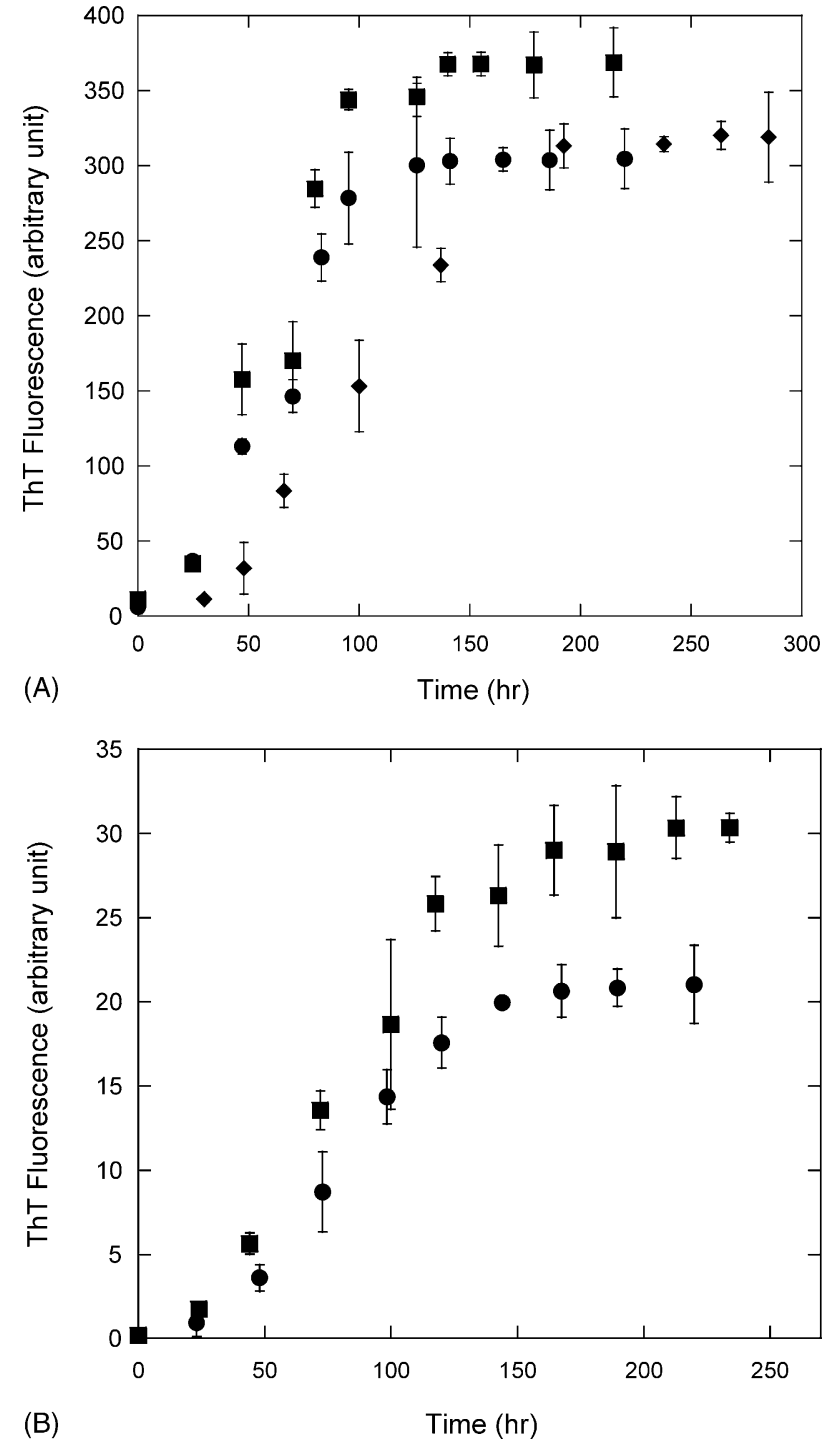

Fig. 1. Effect of solvent type used on the aggregation kinetics of $A \beta$ peptides (A) $A \beta(1-40)$ and (B) $A \beta(25-35)$. The extent of aggregation was measured via ThT fluorescence as a function of elapsed time of aggregation. $A \beta$ peptides were dissolved in three initial solvents (circle: DMSO-PBS; square: TFA-PBS; diamond: urea-PBS) prior to dilution into PBS. Data represent the mean ThT fluorescence measurement of at least six independent experiments $(n \geq 6)$. Error bars represent the standard deviation (S.D.) of the fluorescence measurement.

\subsection{Ultrastructure of aggregates}

Fig. 2A-C show the electron micrographs of aged $\mathrm{A} \beta(1-40)$ peptide ( 9 days after initiation of the aggregation process) in the solvent environments of $100 \%$ DMSO-PBS, $0.1 \%$ (v/v) TFA-PBS, and 8 M urea-PBS, respectively. These electron micrographs confirm the presence of amyloid fibrils/aggregated species in aged samples of $A \beta(1-40)$ prepared from all the stock solutions (Fig. 2A-C). As can be seen in Fig. $2 \mathrm{~A}-\mathrm{C}$, there is a slight difference in morphological feature among aggregates/fibrillar species from these three solvent environments. The ones in urea-PBS system seemed to be shorter in length and larger in cross-sectional area. No 

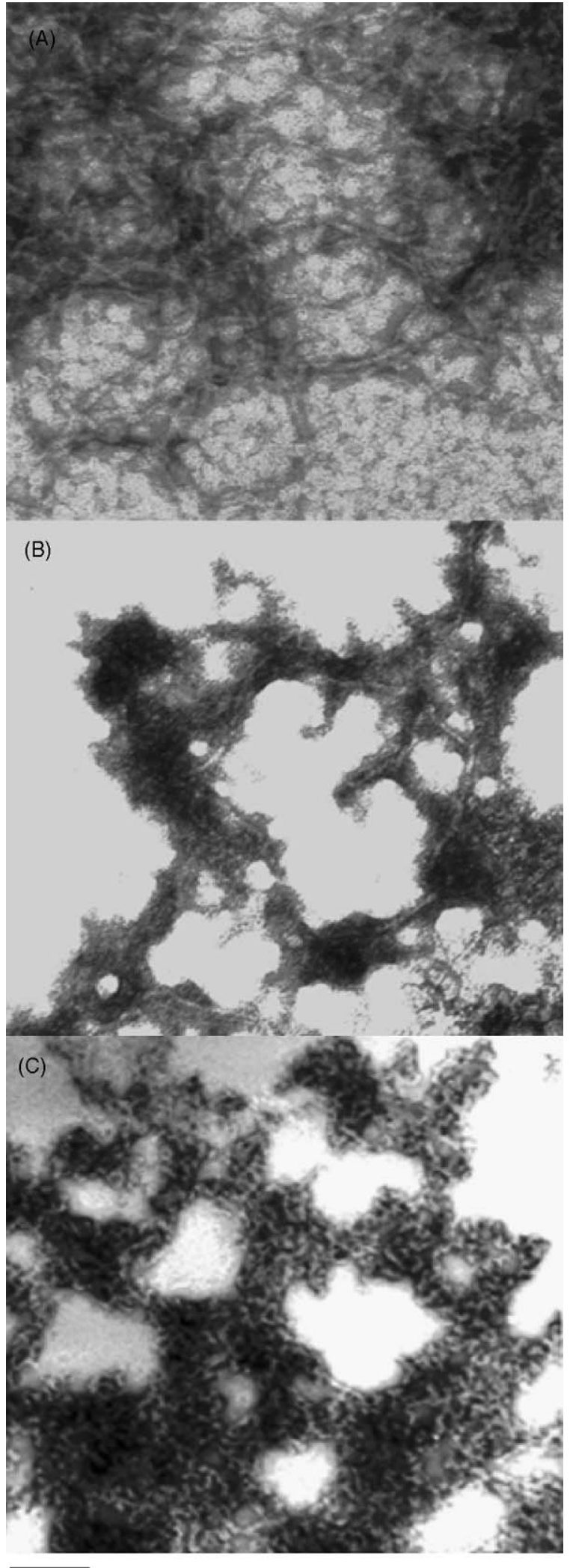

$\overline{100 \mathrm{~nm}}$

Fig. 2. Electron micrographs of negatively stained $A \beta(1-40)$ peptides prepared in different solvent environments. (A) Aggregated $A \beta$ prepared in DMSO-PBS; (B) aggregated A $\beta$ prepared in TFA-PBS; (C) aggregated A $\beta$ prepared in urea-PBS.
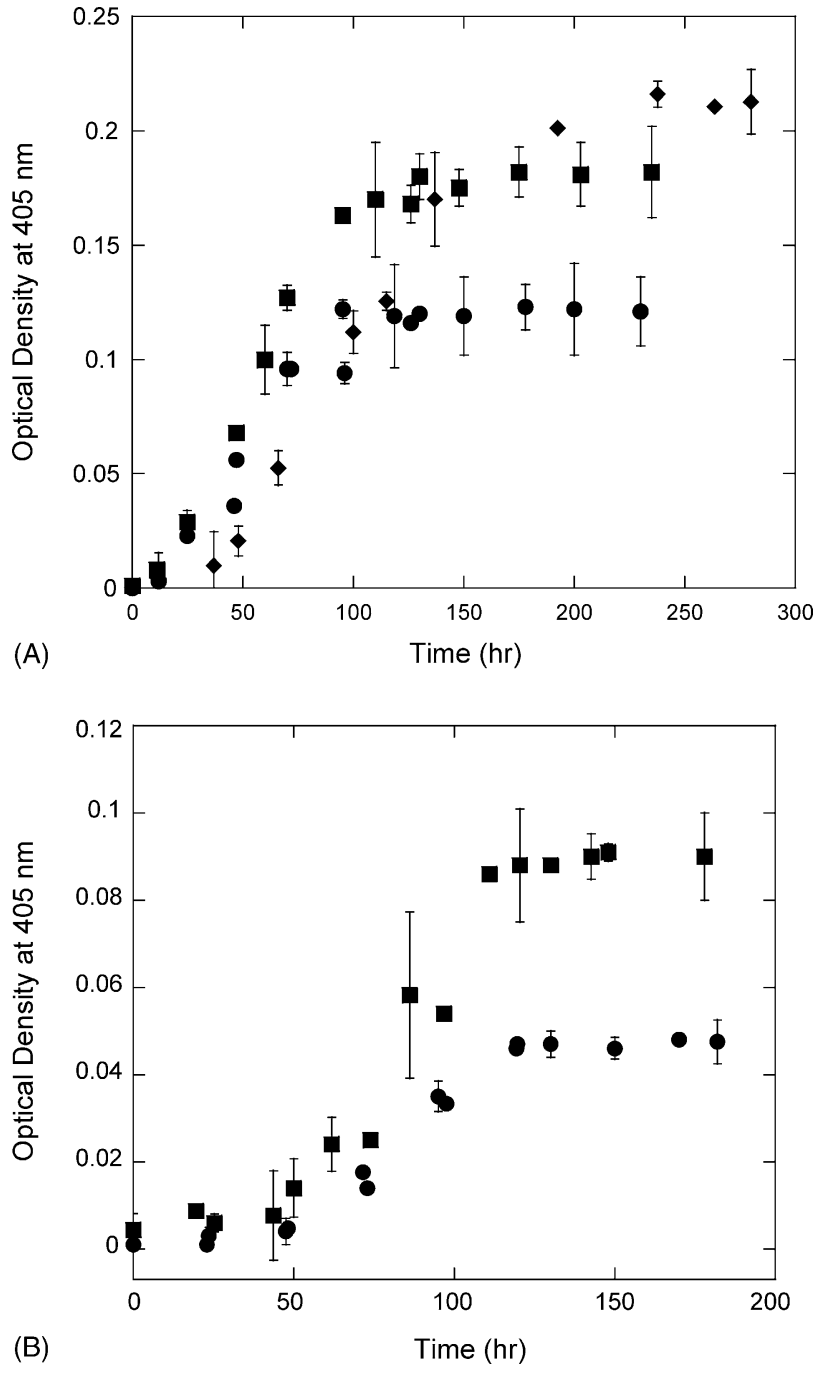

Fig. 3. Effect of solvent type used on the aggregation kinetics of $A \beta$ peptides (A) $A \beta(1-40)$ (B) $A \beta(25-35)$. The extent of aggregation was measured via absorbance at $405 \mathrm{~nm}$ as a function of elapsed time. $A \beta$ peptides were dissolved in three initial solvents (circle: DMSO-PBS; square: TFA-PBS; diamond: urea-PBS) prior to dilution into PBS. Data represent the mean absorbance measurement of at least six independent experiments $(n \geq 6)$. Error bars represent the standard deviation (S.D.) of the absorbance measurement.

aggregated species/or fibrils were found in fresh samples of $A \beta(1-40)$, regardless of the solvents utilized (micrographs not shown).

\subsection{Aggregation kinetics monitored via turbidity measurements}

The extent of aggregation of $\mathrm{A} \beta(1-40)$ peptide was determined as a function of time in different solvent conditions (Fig. 3A). The absorbance/or turbidity of the solution measured at $405 \mathrm{~nm}$ was used as an indication of the degree of aggregation. Fig. 4 shows the difference in behavior of the $A \beta(1-40)$ aggregation as portrayed by the response curves in the three different solvent conditions. Under the same incubation condition $\left(25^{\circ} \mathrm{C}\right.$ and $60 \mathrm{rpm}$ rotation $), \mathrm{A} \beta(1-40)$ peptide 

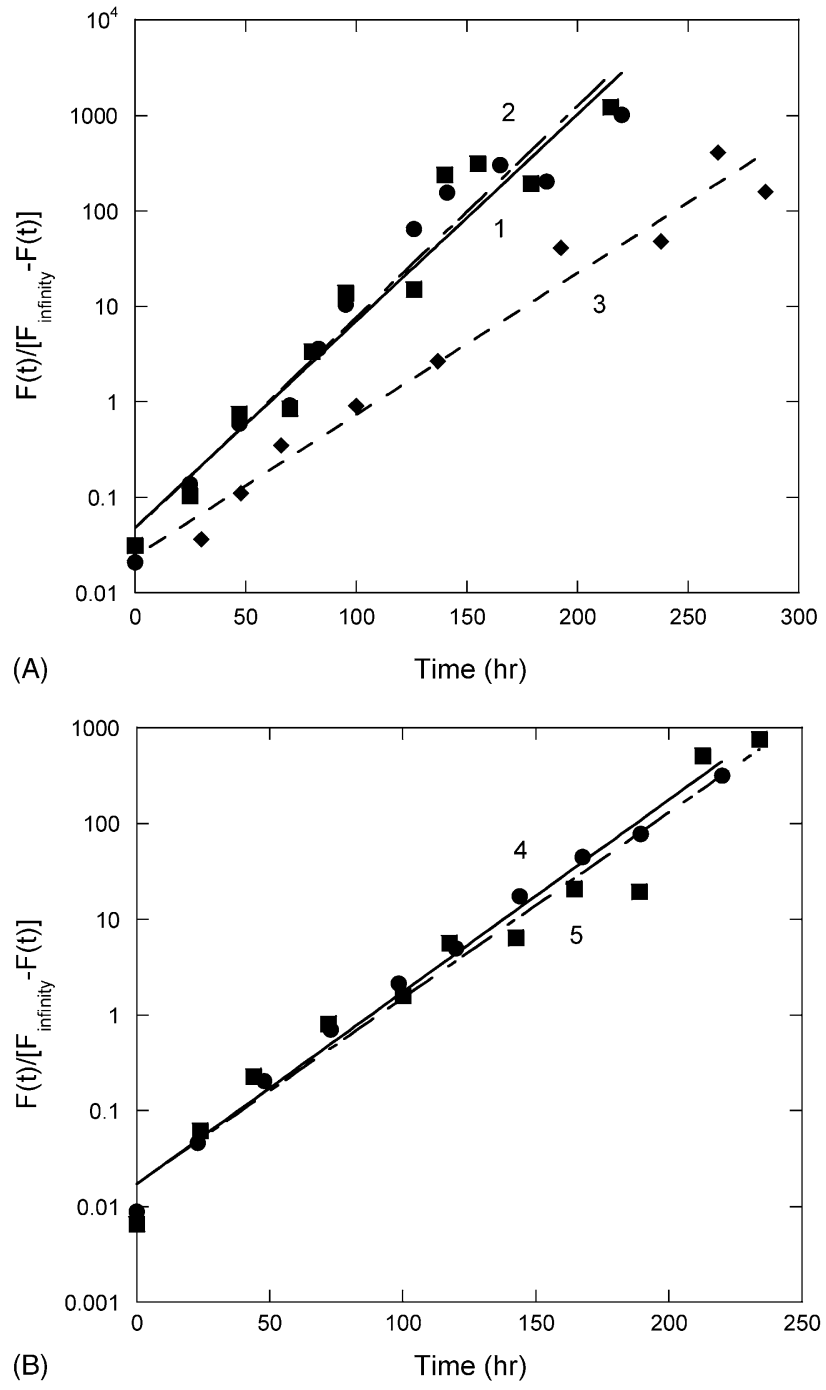

Fig. 4. Semilogarithmical plots of the value $F(t) /[F(\infty)-F(t)]$ vs. elapsed time. $F(t)$ represents the ThT fluorescence emitted by aggregated $\mathrm{A} \beta$ peptides: (A) $\mathrm{A} \beta(1-40)$ (B) $\mathrm{A} \beta(25-35)$ as a function of time. $F(\infty)$ is determined by the plateau value of $F(t)$. Data points (circle: DMSO-PBS; square: TFA-PBS; diamond: urea-PBS) represent the mean value obtained from at least six independent experiments $(n \geq 6)$. Linear least-square fitting was conducted for each straight line (line 1: DMSO-PBS, $R^{2}=0.95$; line 2 : TFA-PBS, $R^{2}=0.94$; line 3: urea-PBS, $R^{2}=0.97$; line 4: DMSO-PBS, $R^{2}=0.99 ;$ line 5: TFA-PBS, $R^{2}=0.96$ ).

initially prepared in $0.1 \%$ (v/v) TFA aggregated within shorter lag period and higher maximal absorbance in comparison to the $\mathrm{A} \beta(1-40)$ in pure DMSO-PBS and 8 M urea-PBS.

We also examined the kinetic behavior of peptide fragment $A \beta(25-35)$ during the course of aggregation (Fig. 3B). Similar to the trend observed for $A \beta(1-40)$, the absorbance of $\mathrm{A} \beta(25-35)$ peptide in $0.1 \%$ (v/v) TFA-PBS solution increased more rapidly than that detected in $100 \%$ DMSO-PBS solution (Fig. 3B) or $8 \mathrm{M}$ urea-PBS buffer before reaching equilibrium (data not shown).

Wang et al. reported differences in the structure of newly made $A \beta$ samples prepared from stock solutions in DMSO and TFA on the native PAGE gels [52]. The fresh samples from $100 \%$ DMSO solvent diluted into water possessed a single species with the approximate molecular weight of an $\mathrm{A} \beta$ monomer; however, fresh samples solubilized with the same initial solvent prior to dilution into PBS migrated as at least two species, most likely a monomer and a dimer. Fresh samples from $0.1 \%$ TFA solvent diluted in either water or PBS migrated as two species as well. Taken altogether with the kinetic data, it has been suspected that the presence of these smaller soluble structured species (bigger than monomer) in the TFA-PBS and DMSO-PBS systems might act as seeds for generating new aggregates.

It is known that the rate of $\beta$-amyloid aggregation/or $\mathrm{A} \beta$ fibril formation could be elevated by the presence of prefibrillar species, a phenomena called as seeding effect $[9,39,54]$. The existence of tracer amount of seed aggregates can essentially reduce the lag phase in the spontaneous self-association of $A \beta$ monomers into larger fibrillar species [9,54]. It is hypothesized that seeding apparently eliminates the requirement for de novo formation of nuclei, a much slower process relative to the growth of nucleated aggregates [41]. This seeding effect is considered a characteristic of a nucleation-dependent elongation mechanism $[13,17]$ and has been observed not only in the case of $A \beta$ proteins but also in other amyloid proteins $[23,24,32]$.

\subsection{Analysis of kinetic data}

Several investigators have reported the kinetics of $\beta$ amyloid peptide aggregation $[33,34,36,41,50]$; however, little effort has been made to examine the effect of initial solvent conditions for dissolving lyophilized $A \beta$ powder on the kinetics behavior. Since the process of aggregation relies on the initial state of peptide, while the initial conformation of peptide is dependent on the solvents used for dissolving lyophilized $\mathrm{A} \beta$ peptide, careful study on the effect of solvents in use for aggregation kinetics is of paramount importance.

In order to make a quantitative comparison of the results from the three different solvent systems, three various kinetic models were utilized to analyze our experimental data.

\subsubsection{Model I}

The time-dependent fluorescence data of the $\mathrm{A} \beta$ peptide aggregation was reported to be described by the following equation $[33,34]$ :

$\ln \left[\frac{F(t)}{F(\infty)-F(t)}\right]=c_{1} t+c_{2}$

where $t$ is the duration time of aggregation, $F(t)$ the ThT fluorescence intensity at time $t, F(\infty)$ the tentatively determined when the fluorescence intensity reach a plateau, and $c_{1}, c_{2}$ are constants determined by experimental data. As we can see in Fig. 4A $(\mathrm{A} \beta(1-40))$ and $4 \mathrm{~B}(\mathrm{~A} \beta(25-35))$, regardless of the solvent systems used, the logarithmic value of the ratio between $F(t)$ and $F(\infty)-F(t)$ is undoubtedly linear proportional to the duration time of the aggregation process. In 
Table 1

Values of parameters in model I for aggregation of $\mathrm{A} \beta$ peptides

\begin{tabular}{lll}
\hline $\mathrm{A} \beta(25-35)^{\mathrm{a}}$ & Slope $\left(c_{1}\right)^{\mathrm{b}}$ & Intercept $\left(c_{2}\right)^{\mathrm{b}}$ \\
\hline $100 \%$ DMSO-PBS & 0.046 & -4.068 \\
$0.1 \%(\mathrm{v} / \mathrm{v})$ TFA-PBS & 0.045 & -4.058 \\
$8 \mathrm{M}$ Urea-PBS & N/A & N/A \\
& & \\
$\mathrm{A} \beta(1-40)^{\mathrm{a}}$ & Slope $\left(c_{1}\right)^{\mathrm{b}}$ & Intercept $\left(c_{2}\right)^{\mathrm{b}}$ \\
\hline $100 \%$ DMSO-PBS & 0.050 & -3.038 \\
$0.1 \%(\mathrm{v} / \mathrm{v})$ TFA-PBS & 0.051 & -3.074 \\
$8 \mathrm{M}$ Urea-PBS & 0.034 & -3.727 \\
\hline
\end{tabular}

${ }^{\mathrm{a}} \mathrm{A} \beta$ peptide concentration $=50 \mu \mathrm{M}$.

$\mathrm{b}$ Value of parameters, $c_{1}$ and $c_{2}$, were obtained by linear regression via the model I.

addition, the slopes of response curves for DMSO-PBS and TFA-PBS were very similar while a more gradual slope and smaller intercept was observed for the urea-PBS solvent system. The slopes $\left(c_{1}\right)$ and intercepts $\left(c_{2}\right)$ for all three solvent systems are summarized in Table 1.

\subsubsection{Model II}

Ample evidence suggests that the so-called nucleationbased polymerization model has been widely employed to analyze phenomena or behaviors with a sigmoidal timecourse response curve, in particular the $A \beta$ fibril formation process $[1,3,22,35,37,40]$. In general, the model consists of a lot of differential equations and solution of the system requires extensive numerical calculations. However, studies showed that the resultant sigmoidal response curve of this complex system could be well represented by a simple stretched exponential decay function listed as follows $[1,12,18,22,47]$ :

$F(t)=F(\infty)+\Delta F \exp \left\{-[k t]^{n}\right\}$

where $t$ is the duration time of aggregation, $F(t)$ the observed ThT fluorescence intensity at time $t, F(\infty)$ the final ThT fluorescence intensity, $\Delta F$ the ThT fluorescence difference between time $t=0$ and $\infty$, and $k$ is the rate constant of fibril formation.

The values of parameters $k$ and $n$ for the three solvent systems, determined by the non-linear least squares curve fitting, are shown in Table 2. Fig. 5A and B also show the best fits

Table 2

Values of parameters in model II for fibril formation of $\mathrm{A} \beta$ peptides

\begin{tabular}{lll}
\hline $\mathrm{A} \beta(25-35)^{\mathrm{a}}$ & $k^{\mathrm{b}}$ & $n^{\mathrm{b}}$ \\
\hline $100 \%$ DMSO-PBS & 0.011 & 2.489 \\
$0.1 \%(\mathrm{v} / \mathrm{v})$ TFA-PBS & 0.010 & 2.031 \\
$8 \mathrm{M}$ Urea-PBS & N/A & N/A \\
& & $n^{\mathrm{b}}$ \\
$\mathrm{A} \beta(1-40)^{\mathrm{a}}$ & $k^{\mathrm{b}}$ & 2.466 \\
$100 \%$ DMSO-PBS & 0.014 & 2.263 \\
$0.1 \%(\mathrm{v} / \mathrm{v})$ TFA-PBS & 0.014 & 2.390 \\
$8 \mathrm{M}$ Urea-PBS & 0.008 & \\
\hline
\end{tabular}

${ }^{\mathrm{a}} \mathrm{A} \beta$ peptide concentration $=50 \mu \mathrm{M}$.

b Values of parameters, $k$ and $n$, were obtained by linear regression via the model II.
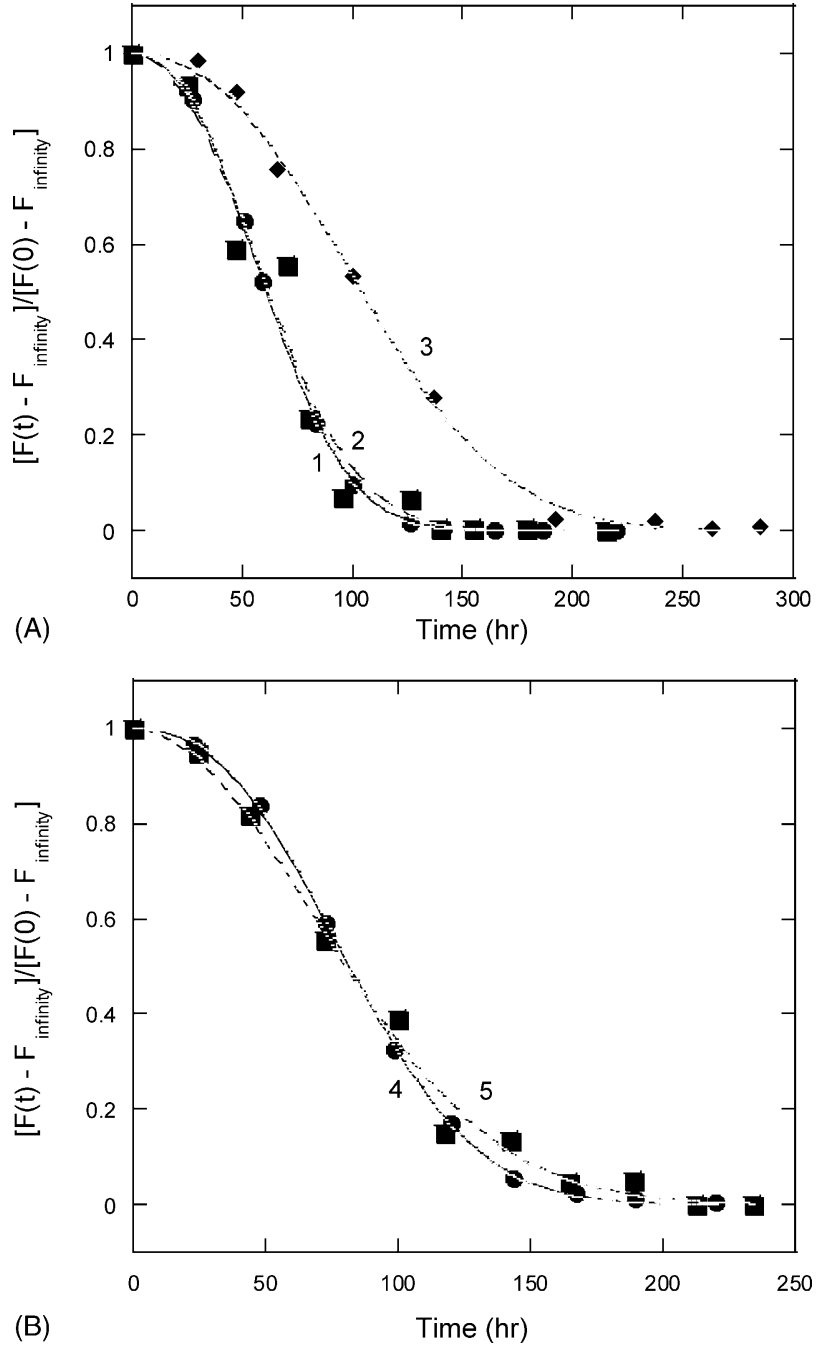

Fig. 5. Plots of the value $[F(t)-F(\infty)] /[F(0)-F(\infty)]$ vs. elapsed time $F(t)$ represents the ThT fluorescence emitted by fibrillar $\mathrm{A} \beta$ peptides: (A) $\mathrm{A} \beta(1-40)(\mathrm{B}) \mathrm{A} \beta(25-35)$ as a function of time. $F(\infty)$ is determined by the plateau value of $F(t)$. Data points (circle: DMSO-PBS; square: TFA-PBS; diamond: urea-PBS) represent the mean value obtained from at least six independent experiments $(n \geq 6)$. The best fit of model II was obtained via the non-linear regression analysis (line 1: DMSO-PBS, $R^{2}=0.95$; line 2: TFA-PBS, $R^{2}=0.96$; line 3: urea-PBS, $R^{2}=0.98$; line 4: DMSO-PBS, $R^{2}=0.96$; line 5: TFA-PBS, $R^{2}=0.97$ ).

of our model equation (Eq. (2)) to the experimental data for $A \beta(1-40)$ and $A \beta(25-35)$, respectively. As depicted in the figures, the curves are in a good agreement with the experimental data. It has been suggested that, for $n>1$, the response curves represent a sigmoidal transition with an initial lag phase, indicative of the involvement of intermediate species. In addition, the value of $k$ can be viewed as a inverse of the relaxation time $[12,22]$. Three points can be concluded from our results: (1) full-length peptide $(\mathrm{A} \beta(1-40))$ formed fibrils faster than its fragment $(\mathrm{A} \beta(25-35))$ under the same solvent condition; (2) rate constant for DMSO-PBS or TFA-PBS was higher than that for urea-PBS, reflecting the absence of seeding effect for urea-PBS solvent system; (3) the relaxation time followed the order: $A \beta(1-40)$ in urea $>A \beta(25-35)$ 
in DMSO-PBS or TFA-PBS $>$ A $\beta(1-40)$ in DMSO-PBS or TFA-PBS.

\subsubsection{Model III}

The reaction mechanism proposed by Kamihira et al. for human calcitonin aggregation was adopted to describe and monitor the $A \beta$ aggregation process [19]:

(a) $[M] \ll \mathrm{CMC}$

$n M \stackrel{k_{\mathrm{n}}}{\longrightarrow} P_{n}$

rate of fibril formation by Eq. (1) $=\left\{\frac{\mathrm{d} f(t)}{\mathrm{d} t}\right\}_{1}=k_{\mathrm{n}}(1-$ $f(t))$.

(b) $[M] \gg \mathrm{CMC}$

$M_{n_{0}}($ micelle $) \rightleftharpoons n_{0} M \stackrel{k_{\mathrm{e}}}{\longrightarrow} P_{n}$

$M+P_{n} \stackrel{k_{\mathrm{e}}}{\longrightarrow} P_{n+1}$

rate of fibril formation by Eq. $(2)=\left\{\frac{\mathrm{d} f(t)}{\mathrm{d} t}\right\}_{2}=$ $k_{\mathrm{e}}[M] f(t)(1-f(t))$ overall rate of fibril formation $=\left\{\frac{\mathrm{d} f(t)}{\mathrm{d} t}\right\}_{1}+\left\{\frac{\mathrm{d} f(t)}{\mathrm{d} t}\right\}_{2}$

$$
\begin{aligned}
f(t) & =\frac{\rho\{\exp [(1+\rho) k t]-1\}}{\{1+\rho \exp [(1+\rho) k t]\}}, \quad k=k_{\mathrm{e}}[M], \\
\rho & =k_{\mathrm{n}} / k ; \text { initial condition }: t=0, f=0
\end{aligned}
$$

where $k_{\mathrm{n}}$ and $k_{\mathrm{e}}$ are reaction constants of reactions 1 and 2 , respectively, CMC denotes the critical micelle concentration, $[M]$ the initial concentration of $\mathrm{A} \beta, M_{n_{0}}$ represents the micelle, $f(t)$ the fraction of aggregated form in the system, $P_{n}$ is the nucleus of fibril with $n \mathrm{~A} \beta$ molecules while $P_{n+1}$ the extended fibril with $n+1$ molecules of $\mathrm{A} \beta$.

The experimental absorbance values were transformed into a fraction of aggregated form. The best fits for plots of fraction of aggregated form against time elapsed are demonstrated in Fig. 6A $(A \beta(1-40))$ and $B(A \beta(25-35))$. As can be seen in Fig. $6 \mathrm{~A}$ and $\mathrm{B}$, the theoretical curve fits the experimental data fairly well indicating congruity of this hypothesized model. The associated kinetic parameters of these best fits are summarized in Table 3 . The ratio of rate
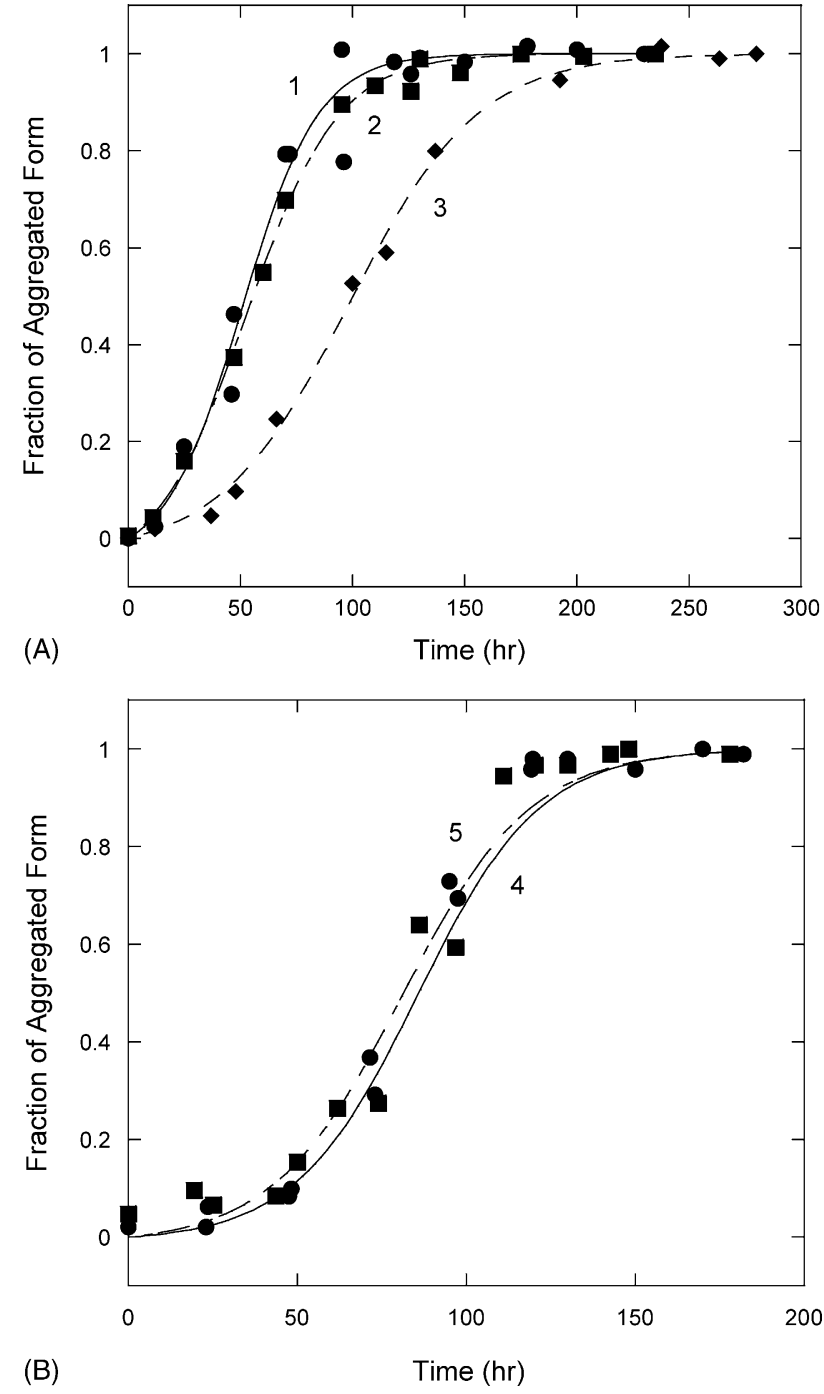

Fig. 6. Time course of the $A \beta$ aggregated fraction after the initiation of the aggregation process. Values of $A \beta(A: A \beta(1-40)$ and $B: A \beta(25-35))$ aggregated fraction were transformed from absorbance values. Each point represents the average of at least six independent measurements $(n \geq 6)$. The best fit of model III to the experimental data was obtained via the nonlinear regression analysis (line 1: DMSO-PBS, $R^{2}=0.97$; line 2: TFA-PBS, $R^{2}=0.99$; line 3: urea-PBS, $R^{2}=0.99$; line 4: DMSO-PBS, $R^{2}=0.98$; line 5: TFA-PBS, $R^{2}=0.97$ ).

Table 3

\begin{tabular}{|c|c|c|c|}
\hline$A \beta(25-35)^{\mathrm{a}}$ & Rate constant $k_{\mathrm{n}}\left(\mathrm{h}^{-1}\right)^{\mathrm{b}}$ & Rate constant $k_{\mathrm{e}}\left(\mathrm{M}^{-1} \mathrm{~h}^{-1}\right)^{\mathrm{b}}$ & Effective rate constant $k_{\mathrm{e}}[M]\left(\mathrm{h}^{-1}\right)^{\mathrm{b}}$ \\
\hline $100 \%$ DMSO-PBS & 0.0005 & 0.0011 & 0.0547 \\
\hline $0.1 \%(\mathrm{v} / \mathrm{v}) \mathrm{TFA}-\mathrm{PBS}$ & 0.0007 & 0.0010 & 0.0516 \\
\hline $8 \mathrm{M}$ Urea-PBS & N/A & N/A & N/A \\
\hline $\mathrm{A} \beta(1-40)^{\mathrm{a}}$ & Rate constant $k_{\mathrm{n}}\left(\mathrm{h}^{-1}\right)^{\mathrm{b}}$ & Rate constant $k_{\mathrm{e}}\left(\mathrm{M}^{-1} \mathrm{~h}^{-1}\right)^{\mathrm{b}}$ & Effective rate constant $k_{\mathrm{e}}[M]\left(\mathrm{h}^{-1}\right)^{\mathrm{b}}$ \\
\hline $100 \%$ DMSO-PBS & 0.0028 & 0.0011 & 0.0562 \\
\hline $0.1 \%(\mathrm{v} / \mathrm{v}) \mathrm{TFA}-\mathrm{PBS}$ & 0.0035 & 0.0009 & 0.0451 \\
\hline $8 \mathrm{M}$ Urea-PBS & 0.0011 & 0.0007 & 0.0336 \\
\hline
\end{tabular}

Rate constants, $k_{\mathrm{n}}$, and $k_{\mathrm{e}}$, for aggregation process of $\mathrm{A} \beta$ peptides in various solvent environments

a $\mathrm{A} \beta$ peptide concentration $=50 \mu \mathrm{M}$.

b Values of rate constants were obtained by non-linear regression via the model III. 
constants $\left(k_{\mathrm{n}} / k_{\mathrm{e}}\right.$ or $\left.k_{\mathrm{n}} / k_{\mathrm{e}}[M]\right)$ represents the relative magnitude between two the nucleation and elongation steps, also suggesting the presence of seeding effect. As listed in Table 3, for both $A \beta(1-40)$ as well as $A \beta(25-35)$, the ratio between rate constants of Eqs. (3) and (4) $\left(k_{\mathrm{n}} / k_{\mathrm{e}}\right)$ or the ratio between rate constant of Eq. (3) and effective rate constant of Eq. (4) $\left(k_{\mathrm{n}} / k_{\mathrm{e}}[M]\right)$ are presented in the following order: TFA-PBS $>$ DMSO-PBS $>$ urea-PBS. Additionally, the value of $k_{\mathrm{n}}$ for $\mathrm{A} \beta(1-40)$ is larger than $k_{\mathrm{e}}$ while $k_{\mathrm{n}}$ is smaller than $k_{\mathrm{e}}$ in the case of $\mathrm{A} \beta(25-35)$. It is also noted that, for full-length peptide $A \beta(1-40)$, the difference between the rate constants of the two reactions varies with the type of solvent system used. The smallest difference was observed for the urea-PBS solvent system. Moreover, with the same order of magnitude of $k_{\mathrm{e}}$, the largest and the smallest reaction rate constants of the nucleation step (Eq. (3)) were obtained for TFA-PBS and urea-PBS, respectively, suggestive of the shortest lag time being reaction in TFA-PBS while longest being in urea-PBS. All data through our analysis implied the higher probability of seeded aggregates present in the TFA-PBS and DMSO-PBS. However, this trend was not conceived for the $A \beta(25-35)$ peptide in either TFA-PBS or DMSO-PBS.

A few other kinetic models on the $A \beta$ aggregation have also been proposed in the literature. Using turbidity measurement on naturally-occurring $A \beta$ variant and its peptide fragments, Jarrett et al. presented a qualitative kinetic model for $A \beta$ self-assembly [16]. They reported that a delayed period was observed for $A \beta(1-39)$ and $A \beta(1-40)$ but not for $A \beta(1-42)$. Two points were made by these authors: (1) the nuclei formation was the rate-determining step in amyloidogenesis; (2) the longer $A \beta(1-42)$ peptide was capable of expediting nucleation of $A \beta(1-40)$. The dynamic light scattering technique was utilized to examine the kinetic phenomena of A $\beta$ self-assembly [51]. The growth of aggregates followed diffusion-limited irreversible end-to-end association of shorter rod-like fibrils. In addition, the size of aggregates increased with decreasing growth rate.

In the non-physiological condition $(\mathrm{pH} \sim 1.0)$, via quasielastic light-scattering spectroscopy and the calculation of hydrodynamic radius, Lomakin et al. studied the aggregation process of $A \beta(1-40)$ and proposed a fairly detailed and complex mathematical model [28]. The authors found that, when $\mathrm{A} \beta$ concentration was above $0.1 \mathrm{mM}$, the initial elongation rate of $A \beta$ or the final size of the aggregates did not present as the function of peptide concentration. However, below a peptide concentration of $0.1 \mathrm{mM}$, the initial elongation rate was proportional to the $A \beta$ concentration, and the resulting fibrils were significantly longer than those formed at higher concentration. Aside from the two-stage model presented by most researchers, Taylor et al., using $A \beta(1-40)$, proposed a three-step aggregation kinetic scheme [50]: the unactivated monomeric $A \beta$ species were first slowly converted into activated monomeric conformer. Then an oligomeric nucleus with growing site for fibril formation was produced by these activated monomeric species in a cooperative man- ner. Finally, unactivated monomers were successively added to the nucleus resulting in the size expansion of the aggregates.

\subsection{Examination of hydrophobicity during the course of aggregation}

Due to an apparent hydrophobicity of the C-terminus on $\mathrm{A} \beta$ peptides, hydrophobic interaction has been suggested

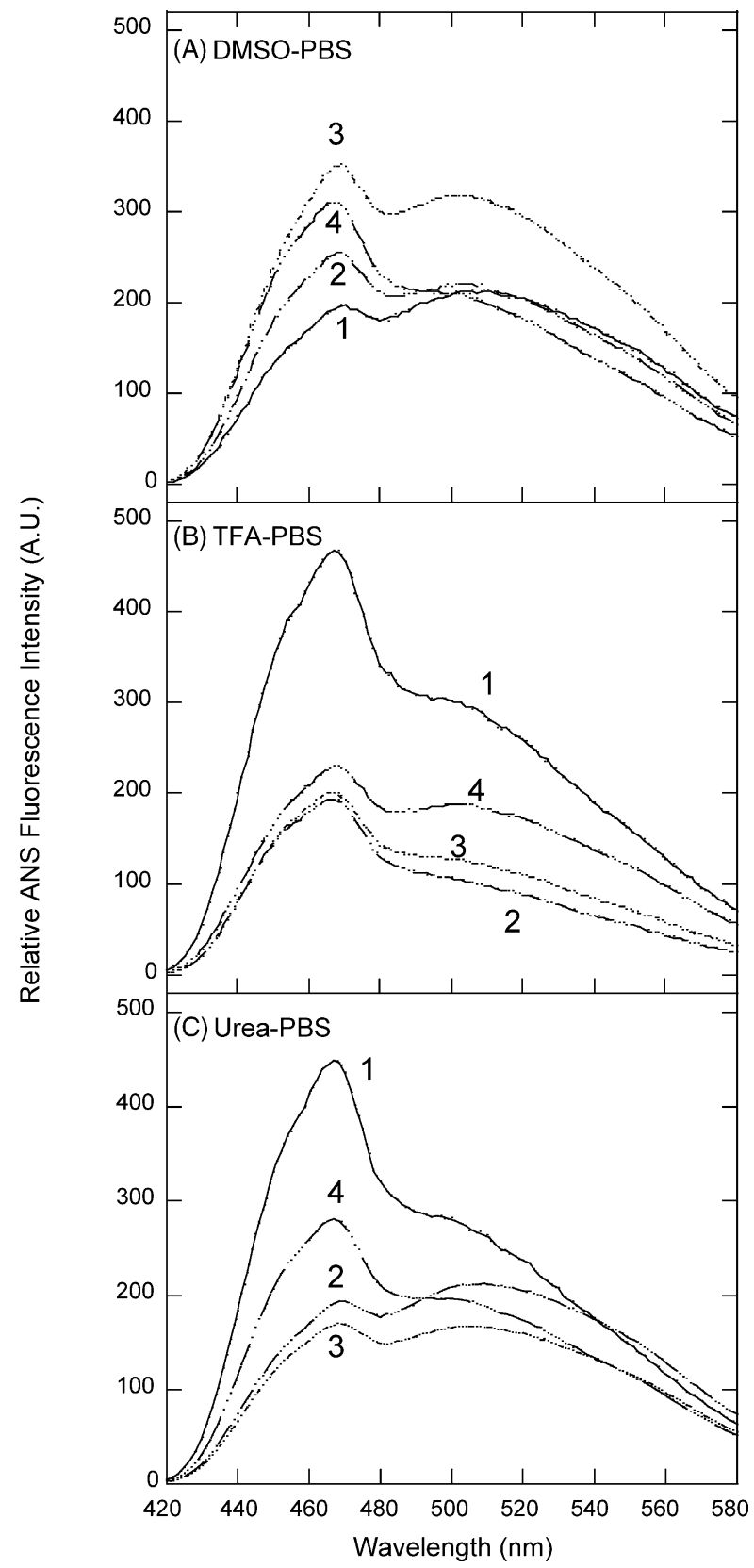

Fig. 7. Effect of solvent environment on the hydrophobicity during the course of aggregation. The hydrophobic property of $A \beta(1-40)$ peptide was measured by ANS-binding fluorescence at different times after the initiation of aggregation. Data were presented as a fluorescence spectra ranging from 420 to $580 \mathrm{~nm}$ and each spectrum was the average of at least three different scans (line 1: $1 \mathrm{~h}$; line 2: $86 \mathrm{~h}$; line 3: $144 \mathrm{~h}$; line 4: $196 \mathrm{~h}$ ). 
to be the major driving force that plays a crucial role in the association of $A \beta$ species. A hydrophobic fluorescent probe, ANS, was shown to interact preferentially with partially folded intermediates and served as a qualitative means for detecting the presence of the aggregated species [45]. Via ANS, we examined the hydrophobic property of $A \beta(1-40)$ peptide in three solvent environments as a function of incubation time.

As depicted in Fig. 7, $1 \mathrm{~h}$ after the initiation of $\mathrm{A} \beta$ aggregation, the DMSO-PBS system (A) showed the lowest ANS-binding fluorescence at around $470 \mathrm{~nm}$ compared with TFA-PBS (B) and urea-PBS (C) systems, suggesting the lowest amount of ANS-binding-competent exposed hydrophobic region in DMSO-PBS initially. The aggregation process began with a decrease followed by an increase in ANS-binding intensity in the case of DMSO-PBS while an opposite trend was observed for TFA-PBS or urea-PBS. In addition, the highest final ANS-fluorescence intensity of DMSO-PBS (DMSO-PBS (310 A.U.) > urea-PBS (280 A.U.) > TFA-PBS (230 A.U.) was indicative of greater hydrophobic exposure of aggregated species initially prepared in $100 \%$ DMSO.

While the underlying mechanisms in regards with the hydrophobic property and their interpretation require further investigations, it appears that the changes in hydrophobicity measured by ANS-binding fluorescence is dependent of surrounding solvent environment. One important thing is that this variation in solvent-dependent transient nature of ANSbinding fluorescence implied the fundamental structural difference in the aggregated species in these three dissolving systems.

\section{Conclusions}

$\beta$-Amyloid is one of at least sixteen different proteins that can fold abnormally to form an amyloid fibril leading to its accompanying pathology $[20,21,25,48,49]$. Numerous studies under different approaches (in vitro, genetic, transgenic animal) have indicated that $A \beta$ has to aggregate into its fibril form before it is toxic to neurons in cultures [38]. It is widely, but not universally, believed that the insoluble species are responsible for the induced neurotoxicity. However, there is no consensus in regards to the exact structure of the aggregated species associated with neurotoxicity.

In this work, ThT fluorescence enhancement, turbidity measurement, transmission electron microscopy, and ANSbinding were employed to monitor the $A \beta$ aggregation kinetics. Our investigations have shown that the aggregation/fibril formation kinetic behavior of $\mathrm{A} \beta$ peptides followed solvent environment-dependent manner. In addition, three reaction schemes/models were used to quantitatively assess the effect of dissolving solvent on the aggregation kinetics of $A \beta$ peptides.

We believe that a basic understanding of the role of initial solvent in determining the aggregation rate and extent, and how $\mathrm{A} \beta$ self-assemble from monomers to larger aggregated species will enables us to comprehend the pathway and key step(s) of $A \beta$ self-association, and thus further aids in the design of potential therapeutic agents.

\section{Acknowledgement}

This work was supported by grants from the National Science Council, Taiwan.

\section{References}

[1] F. Alvarez, A. Alegria, J. Colmenero, Phys. Rev. B 44 (1991) 7306-7312.

[2] M. Arai, T. Inobe, K. Maki, T. Ikura, H. Kihara, Y. Amemiya, K. Kuwajima, Protein Sci. 12 (2003) 672-680.

[3] Y.A. Berlin, A.L. Burin, L.D.A. Siebbeles, M.A. Ratner, J. Phys. Chem. A 105 (2001) 5666-5678.

[4] A. Biswasi, K.P. Das, Protein J. 23 (2004) 529-538.

[5] D. Burdick, B. Soreghan, M. Kwon, J. Kosmoski, M. Knauer, A. Henschen, J. Yates, C. Cotman, C. Glabe, J. Biol. Chem. 267 (1992) 546-554.

[6] J. Busciglio, J. Yeh, B.A. Yankner, J. Neurochem. 61 (1993) 1565-1568.

[7] H.S. Chan, S. Shimizu, H. Kaya, Methods Enzymol. 380 (2004) 350-379.

[8] G. Dutton, Genet. Eng. News 14 (1994) 7-8.

[9] K.C. Evans, E.P. Berger, C.G. Cho, K.H. Weisgraber, P.T. Lansbury Jr., Proc. Natl. Acad. Sci. U.S.A. 92 (1995) 763-767.

[10] B.E. Fischer, Biotechnol. Adv. 12 (1994) 89-101.

[11] W. Garzon-Rodriguez, M. Sepulveda-Becerra, S. Milton, C.G. Glabe, J. Biol. Chem. 272 (1997) 21037-21044.

[12] D. Hamada, C.M. Dobson, Protein Sci. 11 (2002) 2417-2426.

[13] J.D. Harper, P.T. Lansbury Jr., Annu. Rev. Biochem. 66 (1997) 385-407.

[14] D.M. Hartley, D.M. Walsh, C.P. Ye, T. Diehl, S. Vasquez, P.M. Vassilev, D.B. Teplow, D.J. Selkoe, J. Neurosci. 19 (1999) 88768884 .

[15] D.R. Howlett, K.H. Jennings, D.C. Lee, M.S. Clark, F. Brown, R. Wetzel, S.J. Wood, P. Camilleri, G.W. Roberts, Neurodegeneration 4 (1995) 23-32.

[16] J.T. Jarrett, E.P. Berger, P.T. Lansbury Jr., Ann. N.Y. Acad. Sci. 695 (1993) 144-148.

[17] J.T. Jarrett, P.T. Lansbury Jr., Cell 73 (1993) 1055-1058.

[18] P. Jund, R. Jullien, I. Campbell, Phys. Rev. E 6303 (2001).

[19] M. Kamihira, A. Naito, S. Tuzi, A.Y. Nosaka, H. Saito, Protein Sci. 9 (2000) 867-877.

[20] J.W. Kelly, Curr. Opin. Struct. Biol. 8 (1998) 101-106.

[21] J.W. Kelly, Curr. Opin. Struct. Biol. 6 (1996) 11-17.

[22] M. Kodaka, Biophys. Chem. 107 (2004) 243-253.

[23] M.R. Krebs, L.A. Morozova-Roche, K. Daniel, C.V. Robinson, C.M. Dobson, Protein Sci. 13 (2004) 1933-1938.

[24] M.R. Krebs, D.K. Wilkins, E.W. Chung, M.C. Pitkeathly, A.K. Chamberlain, J. Zurdo, C.V. Robinson, C.M. Dobson, J. Mol. Biol. 300 (2000) 541-549.

[25] P.T. Lansbury Jr., Proc. Natl. Acad. Sci. U.S.A. 96 (1999) 3342-3344.

[26] H. Levine, Amyloid 2 (1995) 1-6.

[27] H. LeVine 3rd, Protein Sci. 2 (1993) 404-410.

[28] A. Lomakin, D.S. Chung, G.B. Benedek, D.A. Kirschner, D.B. Teplow, Proc. Natl. Acad. Sci. U.S.A. 93 (1996) 1125-1129.

[29] A. Luzar, D. Chandler, J. Chem. Phys. 98 (1993) 8160-8173. 
[30] A. Luzar, A.K. Soper, D. Chandler, J. Chem. Phys. 99 (1993) 6836-6847.

[31] Y. Migron, Y. Marcus, J. Chem. Soc. Faraday Trans. 87 (1991) 1339-1343.

[32] L.A. Morozova-Roche, J. Zurdo, A. Spencer, W. Noppe, V. Receveur, D.B. Archer, M. Joniau, C.M. Dobson, J. Struct. Biol. 130 (2000) 339-351.

[33] H. Naiki, K. Hasegawa, I. Yamaguchi, H. Nakamura, F. Gejyo, K. Nakakuki, Biochemistry 37 (1998) 17882-17889.

[34] H. Naiki, K. Nakakuki, Lab. Invest. 74 (1996) 374-383.

[35] J. Nelson, R.E. Chandler, Coord. Chem. Rev. 248 (2004) 11811194.

[36] M.M. Pallitto, R.M. Murphy, Biophys. J. 81 (2001) 18051822.

[37] J.C. Phillips, Rep. Prog. Phys. 59 (1996) 1133-1207.

[38] C.J. Pike, A.J. Walencewicz, C.G. Glabe, C.W. Cotman, Eur. J. Pharmacol. 207 (1991) 367-368.

[39] J.C. Rochet, K.A. Conway, P.T. Lansbury Jr., Biochemistry 39 (2000) 10619-10626.

[40] J. Ross, M.O. Vlad, Annu. Rev. Phys. Chem. 50 (1999) 51-78.

[41] R. Sabate, M. Gallardo, J. Estelrich, Biopolymers 71 (2003) 190-195.
[42] B. Seilheimer, B. Bohrmann, L. Bondolfi, F. Muller, D. Stuber, H. Dobeli, J. Struct. Biol. 119 (1997) 59-71.

[43] D.J. Selkoe, J. Neuropathol. Exp. Neurol. 53 (1994) 438-447.

[44] D.J. Selkoe, Trends Neurosci. 16 (1993) 403-409.

[45] G.V. Semisotnov, N.A. Rodionova, O.I. Razgulyaev, V.N. Uversky, A.F. Gripas, R.I. Gilmanshin, Biopolymers 31 (1991) 119-128.

[46] C.L. Shen, R.M. Murphy, Biophys. J. 69 (1995) 640-651.

[47] S.I. Simdyankin, N. Mousseau, Phys. Rev. E 68 (2003).

[48] J.D. Sipe, Annu. Rev. Biochem. 61 (1992) 947-975.

[49] J.D. Sipe, Crit. Rev. Clin. Lab. Sci. 31 (1994) 325-354.

[50] B.M. Taylor, R.W. Sarver, G. Fici, R.A. Poorman, B.S. Lutzke, A. Molinari, T. Kawabe, K. Kappenman, A.E. Buhl, D.E. Epps, J. Protein Chem. 22 (2003) 31-40.

[51] S.J. Tomski, R.M. Murphy, Arch. Biochem. Biophys. 294 (1992) 630-638.

[52] S.S. Wang, S.A. Tobler, T.A. Good, E.J. Fernandez, Biochemistry 42 (2003) 9507-9514.

[53] R.V. Ward, K.H. Jennings, R. Jepras, W. Neville, D.E. Owen, J. Hawkins, G. Christie, J.B. Davis, A. George, E.H. Karran, D.R. Howlett, Biochem. J. 348 (Pt 1) (2000) 137-144.

[54] S.J. Wood, W. Chan, R. Wetzel, Biochemistry 35 (1996) 12623-12628. 